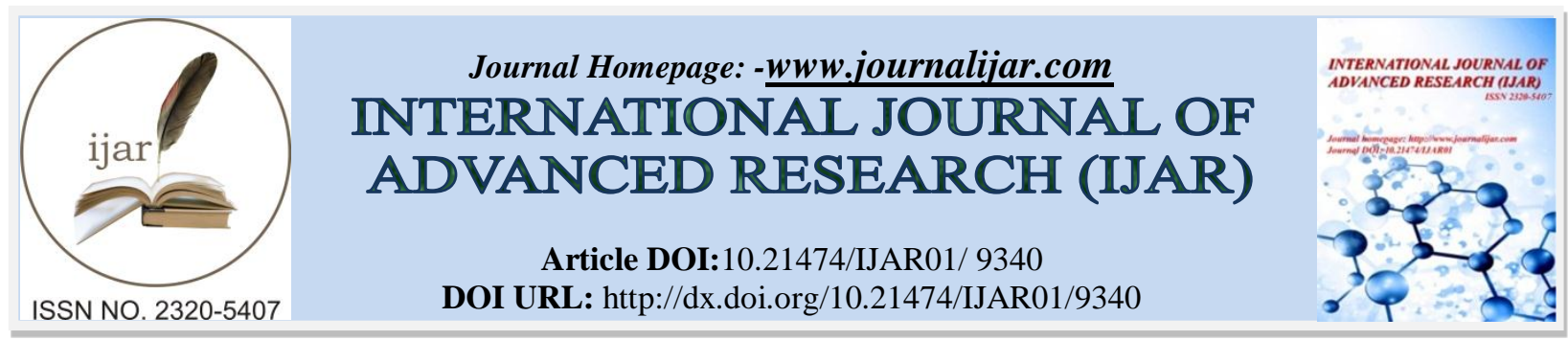

RESEARCH ARTICLE

\title{
A STUDY OF BURNOUT SYNDROME OF PHYSICAL EDUCATION TEACHER IN PURULIA DISTRICT.
}

Sajal Maji ${ }^{1}$ And Sk Hilaluddin ${ }^{2}$.

1. Guest lecturer, Achhruram Memorial College, Jhalda, Purulia.

2. Guest lecturer, Sewnarayan Rameswar Fatepuria College, Beldanga, Murshidabad.

\section{Manuscript Info}

Manuscript History

Received: 04 May 2019

Final Accepted: 06 June 2019

Published: July 2019

Key words:-

Burnout syndroms, Physical education Teachers.

\begin{abstract}
The purpose of the study was, "A study of burnout syndrome of physical education teacher in purulia district." The Researcher selected on the Different schools in purulia district for research purpose. Total 40 subjects for the study in which $(\mathrm{N}=40)$ and with the range of age is 25-45 years was selected for the data collection as per simple randam technique method. After that researcher collects the data, from those teachers with the help of Burnout Syndroms questionnaire.

After the data collection the researcher analyses the data with the help of descriptive statistics (Mean, SD, Percentage).
\end{abstract}

Copy Right, IJAR, 2019,. All rights reserved.

\section{Introduction:-}

Burnout happens when the circumstances of our life no longer work for us, when we are no longer able to cope with the stress of our situation We struggle on, missing or ignoring all the warning signs - working harder and harder, getting less and less done - until our physical and emotional systems begin to fail. We are constantly striving to get control or return to normal yet feel overwhelmed at the task. ${ }^{1}$

In 'normal circumstances', we tend to be motivated, committed, caring, conscientious and highly valued; we have energy, enthusiasm and clarity. In burnout these qualities diminish leaving us confused, lethargic, exhausted, irritated and unable to cope. This is why people who are burned out often see themselves as failing. ${ }^{2}$

The concept was traditionally examined in the context of human services, such as health care, social work, psychotherapy and teaching. One of the most prominent definitions describes burnout as a syndrome of emotional exhaustion, depersonalization, and reduced personal accomplishment that can occur among individuals who work with people in some capacity. ${ }^{3}$

\footnotetext{
${ }^{1}$ Wikipedia:https://jaramuzaretreats.com/stress-burnout/what-is-burnout/(16/03/2016).

2 Schaufeli, W. B., Leiter, M. P. \& Maslach, C. (2009). Burnout: 35 years of research and practice. Career Development International, 14, 204-220.

${ }^{3}$ Maslach, C. \& Leiter, M. P. (1997). The truth about burnout. San Francisco: Jossey Bass. Maslach, C., Schaufeli, W. B. \& Leiter, M. P. (2001). Job burnout. In S. T. Fiske, D. L. Schachter \& C. Zahn-Waxer (Eds.), Annual Review of Psychology, 53, 397-422.
} 
Exhaustion occurs as a result of one's emotional demands. Depersonalization refers to a cynical, negative or detached response to care recipients / patients. The reduced personal accomplishment refers to a belief that one can no longer work effectively with clients / patients / care recipients.

In the late 1980s burnout was more and more noticed also outside the work with patients and care recipients. In a more general way burnout can be seen as "a state of exhaustion in which one is cynical about the value of one's occupation and doubtful of one's capacity to perform". Researchers agree that stressors leading to burnout in human services can also be found in other occupations. One of the most radical definitions representing the general nature of burnout is "Burnout is the index of the dislocation between what people are and what they have to do. It represents an erosion in value, dignity, spirit, and will - an erosion of the human soul. It is a malady that spreads gradually and continuously over time, putting people into a downward spiral from which it's hard to recover." In summary, burnout can be defined as feelings of exhaustion, a cynical attitude toward the job and people involved in the job and through a reduced personal accomplishment or work efficiency. In a radical meaning burnout takes away a person's spirit and will. Contrary to a popular understanding, burnout can be found also outside human service professions. ${ }^{4}$

However, burnout still may be a greater problem 8 in occupations where employees are more in interaction with other people (clients, customers, etc.) rather than dealing with things and information. Researchers agree that burnout does not occur "overnight". It is rather a result of a prolonged and slow process that may last even for years. According to several authors the "triggers" are excessive job demands and the employee's inability to continuously invest energy when meeting the demands. The development of burnout usually begins at an early stage of emotional exhaustion. High levels of emotional exhaustion consequently lead to a withdrawal from the people / clients / patients / customers the employees work with and also from their job in general. Such a withdrawal results in depersonalized reactions to people / clients / patients / customers and in a cynical attitude towards the job. ${ }^{5}$

In other words, emotional exhaustion may lead to the depersonalization stage of burnout. However, several authors claim that exhaustion and depersonalization develop rather parallel and have different antecedents. The development of burnout follows two processes." The first process is related to job demands which lead to frequent overtaxing and consequently to exhaustion. A lack of job resources (e.g., lack of social support), on the other hand, represents a second process which in the end leads to disengagement from work. If resources are not functional in meeting job demands, withdrawal behavior from work will occur. Withdrawal behavior consequently leads to disengagement which refers to "distancing oneself from one's work, and experiencing negative attitudes toward the work object, work content, and one's work in general". The third component of 9 burnout, reduced personal accomplishment, is rather incidental in that process and is not seen as a core dimension of burnout.

\section{Review Of Related Literatures}

Freddi $\mathrm{M}$ et al., (2003) ${ }^{6}$ Emotional exhaustion, depersonalisation and personal achievement represent the main dimensions of the "burn-out syndrome" (B.O.). The risk of B.O. is especially elevated among people working in helping professions. These professionals work in settings that are characterized by a very strong emotional involvement. The representative sample of this study consisted of 100 subjects of whom a part of them worked in a psychiatric setting and others who didn't. All of them have been assessed through the M.B.I. and the E.P.Q. The purpose of the present study was especially: 1) to explore the existence of B.O. and its level, and 2) to verify the existence of some personality characteristics of employees which could be considered as possible predictors of B.O. syndrome. The statistical analysis showed that the three B.O. dimensions and therefore the B.O. syndrome were within the group of persons working in helping professions. The outcomes of this study encouraged an intervention focused on three parts: job organisation, self-management of psychological well-being and teamwork effectiveness.

\footnotetext{
${ }^{4}$ Lee, R. T. \& Ashforth, B. E. (1993). A further examination of managerial burnout: Toward an integrated model. Journal of Organizational Behavior, 14, 3-20.

${ }^{5}$ Schaufeli, W. B. \& Schreurs, P. J. G. (2005). Are there causal relationships between the dimensions of the Maslach Burnout Inventory? A review and two longitudinal tests. Work \& Stress, 19, $238-255$.

${ }^{6}$ Freddi M, Corradi A. Stress, job satisfaction, and quality of life in the health professions: the role of burn-out and personality features. Recenti Prog Med. 2003, 94(12):545-8.
} 
Bauer J et al., (2003) ${ }^{7}$ this paper reviews the scientific concepts and the clinical aspects of the burn-out syndrome. According to recent studies, up to $25 \%$ of the German working population appear to suffer from what the Amercan physician and psychoanalyst, Herbert Freudenberger, has designated in 1974 as "burn-out syndrome". Characteristic features of this syndrome are emotional exhaustion, depersonalization and low personal accomplishment. People affected by the burn-out syndrome may suffer from depressive or anxious symptoms, from sleep disorders, chronic pain syndromes, or functional disorders of the cardiovascular or gastrointestinal system. Primary causes of the burnout syndrome include high demand combined with low influence, a high level of engagement without sufficient rewards or gratification, and a low level of social support. Preventive measures against burn-out include Balint-like supervision groups. In cases of a fully developed burn-out syndrome, affected persons should undergo either psychotherapy or a multimodal psychosomatic therapy.

0Colasudro (1981) ${ }^{\mathbf{8}}$ investigated the magnitude of burnout as measured by self-diagnosis and an established inventory in 215 public school teachers in San Diego. 16\% were rated burned out by the inventory whereas $52 \%$ reported themselves burned out. Burnout was usually frequent at all ages but age group 30-39 was over-represented. The relationship of the variables of sex, grade assignment, ethnic status, marital status, number of children, educational qualification was not statistically significant to the measured burnout and self reported burnout.

\section{Methodology:-}

In this chapter, the selected of subjects, selections of variables and test, instrument reliability, administration of standard questionnaire and the statistical technique used to analysis the data have been discussed.

\section{Selection of subjects}

The researcher would take total 40 subjects for the study in which $(\mathrm{N}=40)$ and with the range of age is 25-45 years. The selected subjects would be from various schools of purulia district physical education teachers.

\section{Sampling design}

The researcher will take simple random sampling technique as appropriate tool for selecting the desire subjects of the study.

\section{Variables of the Study}

Variables for this study is Burnout syndrome

\section{Tools to be used}

Burnout syndromes standard questionnaire are used for this study. Reliability of Maslach Burnout Survey Iwanicki and Sachwab presented evidence substantiating the reliability of this test, when the adaptation was made for use the scale with teachers at least in the instance of the emotional exhaustion subscale for which internal consistency coefficient alpha estimates of reliability were .90 and .89 respectively for the frequency and intensity dimension. For depersonalization sub-scale .76 and .75 and for the personal accomplishment corresponding reliabilities of only .76 and .73 were obtained. Split-half method reliability for the Maslach Burnout Survey has been reported as .74 and .81

Validity of Maslach Burnout Survey Concurrent validity was determined in the following manner, first by correlating sub scales scores with independent behavioral ratings completed by subjects spouses and co-workers and second by correlating sub scale scores with scores on the job diagnostic survey, Hack man \& Oldham; 1975, significant correlation for each of these methods range from .20 to .48 on the emotional exhaustion sub-scale, from .32 to .57 for the depersonalization measure and from .25 to .27 on the personal accomplishment sub scale.

\section{Statistical design}

Primarily the data was analyzed using Mean, SD and percentage scale.

\footnotetext{
${ }^{7}$ Bauer J, Häfner S, Kächele H, Wirsching M, Dahlbender RW.The burn-out syndrome and restoring mental health at the working place.PsychotherPsychosom Med Psychol. 2003 May;53(5):213-22.

${ }^{8}$ Colasudro, M.M. (1981). A descriptive study of professional burnout among public school teachers in San Diego. Dissertation Abstracts international, 42(2), 470A
} 


\section{Data Analysis}

The data collected from different school in Purulia district, Burnout syndrome was put in to statistical formula for analysis which has been present in this chapter. Analysis of Mean, SD and percentage has been employed to analyze the present data and the level of significance set at 0.05 .

\section{Findings}

According to the survey of the variables under present study the analysis of percentage has been applied and the level of significance set at 0.05 levels. The statistical analysis has been presented through following tables-

Raw data and Percentage scale of burnout syndromes of all questions

\begin{tabular}{|c|c|c|c|c|c|c|c|}
\hline $\begin{array}{c}\text { Questi } \\
\text { ons }\end{array}$ & $\begin{array}{c}\text { Nev } \\
\text { er }\end{array}$ & $\begin{array}{c}\text { A few time a year } \\
\text { or less }\end{array}$ & $\begin{array}{c}\text { Once a month } \\
\text { or less }\end{array}$ & $\begin{array}{c}\text { A few times a } \\
\text { month }\end{array}$ & $\begin{array}{c}\text { Once a } \\
\text { week }\end{array}$ & $\begin{array}{c}\text { A few then } \\
\text { week }\end{array}$ & $\begin{array}{c}\text { Every } \\
\text { day }\end{array}$ \\
\hline 1 & 2 & 9 & 5 & 6 & 5 & 9 & 6 \\
\hline 2 & 1 & 3 & 8 & 8 & 6 & 10 & 4 \\
\hline 3 & 1 & 6 & 3 & 7 & 5 & 12 & 6 \\
\hline 4 & 0 & 0 & 7 & 5 & 8 & 10 & 10 \\
\hline 5 & 3 & 6 & 4 & 7 & 4 & 11 & 5 \\
\hline 6 & 4 & 3 & 6 & 4 & 5 & 8 & 10 \\
\hline 7 & 4 & 2 & 4 & 9 & 2 & 13 & 6 \\
\hline 8 & 4 & 5 & 4 & 4 & 12 & 5 & 6 \\
\hline 9 & 1 & 1 & 2 & 12 & 8 & 8 & 8 \\
\hline 10 & 0 & 4 & 9 & 8 & 6 & 7 & 6 \\
\hline 11 & 1 & 4 & 10 & 6 & 4 & 10 & 5 \\
\hline 12 & 1 & 1 & 5 & 7 & 6 & 10 & 9 \\
\hline 13 & 1 & 4 & 8 & 4 & 7 & 7 & 9 \\
\hline 14 & 1 & 6 & 5 & 3 & 5 & 7 & 13 \\
\hline 15 & 6 & 4 & 4 & 5 & 6 & 8 & 7 \\
\hline 16 & 1 & 3 & 8 & 6 & 5 & 7 & 10 \\
\hline 17 & 2 & 4 & 4 & 6 & 6 & 8 & 10 \\
\hline 18 & 1 & 4 & 5 & 7 & 2 & 12 & 9 \\
\hline 19 & 0 & 3 & 5 & 5 & 6 & 6 & 15 \\
\hline 20 & 1 & 4 & 4 & 7 & 3 & 8 & 13 \\
\hline 21 & 1 & 2 & 5 & 8 & 3 & 8 & 13 \\
\hline 22 & 2 & 5 & 8 & 2 & 2 & 5 & 16 \\
\hline
\end{tabular}

In this raw data it show that more than teachers are affected a few than week or every day of daily life

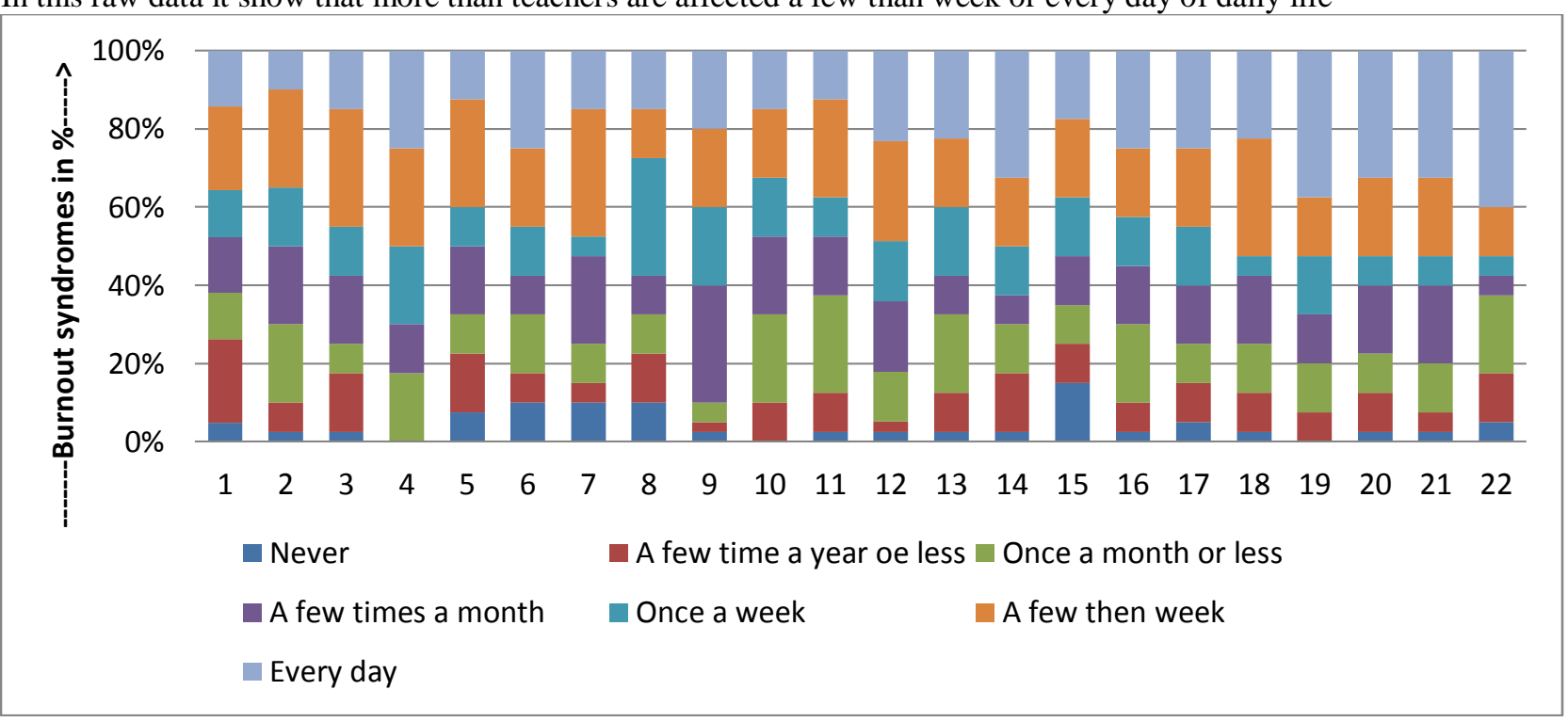




\section{Graphical representation of percentage scale of the burnout syndromes of physical education teachers Discussion of findings:-}

By keeping in mind the importance of the survey taken for the burnout syndromes, the researcher has selected an investigated entitled, "A study of burnout syndrome of physical education teacher in Purulia district". There are 40 teachers from different schools of Purulia district has been selected as subjects. To survey of Burnout syndromes standard questionnaire are used for this study. Reliability of Maslach Burnout Survey Iwanicki and Sachwab presented standard questionnaire has been taken. Undertaking research in the area of burnout syndromes of physical education teachers is needed and is important for our educational society.

So, to survey of burnout syndromes different schools of physical educations in Purulia district. Burnout syndromes could be given help to promote emotional, mental, physical exhaustion by excessive and prolonged stress of physical education teachers in their schools to betterment of teaching and skill practice sititutions of physical education schools. The statistical analysis of data collected on minimum 40 teachers in physical education schools of purulia district.

The result of the present investigation revealed that Burnout syndrome along with the modern era could help to improve upon teachers mental and physical exhaustion. It is a common problem of maximum worker of the society. The result of the present study has been supported by the earlier reports and established the progress of burnout syndromes.

\section{Discussion of Hypothesis}

The result of survey study indicates that the burnout syndromes provide a quantity to evaluate the burnout syndromes of physical education teachers are also found through percentage.

Further, the result inferential statistics indicates that there was statistically no significant difference in burnout syndromes of physical education teachers. This result in turn suggests that the null hypothesis- " $\mathbf{H}_{\mathbf{O}}-\mathbf{T h e r e}$ is no significant difference in burnout syndromes of teacher's had found" has been accepted.

\section{Summary}

The purpose of this study was to find out a study of burn out syndrome from physical education teacher in Purulia district. In this study 40 physical education teachers were taken as a sample. Questionnaire are used for collection of data. Primarily the data was processed with descriptive statistics. For testing hypothesis the level of significance was set at 0.05 . Finally, we found that:

1. The finding of this study showed that the survey of burnout syndrome can be applied to find out the situation of physical education teachers of school through questionnaires. Moreover, percentage scale of every question of the questionnaire is applied. However, accumulating evidence suggest that burnout syndromes may be a useful method to help physical education teachers of schools.

2. Although this study does not claim about its cure but firmly believes that progressive part of secondary schools intervention may obviously it helpful of physical education teachers. However, other researchers being engaged with this field has also been benefited by the result of the present study.

3. From, the variables studied as well as the overall evaluation of the syndrome, showed that as less teachers are never problems in burnout syndrome and above teachers face a burnout syndrome problems in every day life.

\section{Conclusion:-}

Following conclusions were given on the basis of the result-

1. Burnout is a societal problem that won't be solved by limiting work. The survey of burnout syndromes sititutions are less in physical education teachers. But, a few than week or every day burnout syndromes is high in physical education teachers.

2. It concluded that teachers presented evidence they have less teachers not affected by that syndromes, more than teachers are affected every day of his/her daily life by that syndromes of work load, physical exhaustion, fatigue and stress, althrough that can only be inferred by data.

3. We concluded that there is a need for teachers and administrators to have access to this kind of study in order to broaden information and allow greater knowledge of burnout syndrome. 


\section{References:-}

1. Wikipedia:https://jaramuzaretreats.com/stress-burnout/what-is-burnout/(16/03/2016).

2. Schaufeli, W. B., Leiter, M. P. \& Maslach, C. (2009). Burnout: 35 years of research and practice. Career Development International, 14, 204-220.

3. Maslach, C. \& Leiter, M. P. (1997). The truth about burnout. San Francisco: Jossey Bass. Maslach, C., Schaufeli, W. B. \& Leiter, M. P. (2001). Job burnout. In S. T. Fiske, D. L. Schachter \& C. Zahn-Waxer (Eds.), Annual Review of Psychology, 53, 397-422.

4. Lee, R. T. \& Ashforth, B. E. (1993). A further examination of managerial burnout: Toward an integrated model. Journal of Organizational Behavior, 14, 3-20.

5. Schaufeli, W. B. \& Schreurs, P. J. G. (2005). Are there causal relationships between the dimensions of the Maslach Burnout Inventory? A review and two longitudinal tests. Work \& Stress, 19, $238-255$.

6. Freddi M, Corradi A. Stress, job satisfaction, and quality of life in the health professions: the role of burnout and personality features. Recenti Prog Med. 2003, 94(12):545-8.

7. Bauer J, Häfner S, Kächele H, Wirsching M, Dahlbender RW.The burn-out syndrome and restoring mental health at the working place.PsychotherPsychosom Med Psychol. 2003 May;53(5):213-22.

8. Colasudro, M.M. (1981). A descriptive study of professional burnout among public school teachers in San Diego. Dissertation Abstracts international, 42(2), 470A 